\title{
High COX-2 expression contributes to a poor prognosis through the inhibition of chemotherapy-induced senescence in nasopharyngeal carcinoma
}

\author{
CHEN SHI ${ }^{1}$, YONGJUN GUAN ${ }^{2}$, LIANG ZENG ${ }^{3}$, GUIZHU LIU $^{4}$, YINGHONG ZHU ${ }^{2}$, HE XU $^{1,2}$, YICHEN LU $^{1,2}$, \\ JIABIN LIU ${ }^{2}$, JIAOJIAO GUO ${ }^{2}$, XIANGLING FENG ${ }^{5}$, XINYING ZHAO ${ }^{5}$, WEIHONG JIANG ${ }^{6}$, \\ GUANCHENG $\mathrm{LI}^{2}$, GUIYUAN LI ${ }^{2}$, YUN DAI ${ }^{7}$, FENGYAN JIN ${ }^{1}$, WEI LI ${ }^{1}$ and WEN ZHOU ${ }^{2}$ \\ ${ }^{1}$ Cancer Center, The First Hospital of Jilin University, Changchun, Jilin 130021; ${ }^{2}$ Cancer Research Institute; \\ Key Laboratory of Carcinogenesis and Cancer Invasion, Ministry of Education; National Health and \\ Family Planning Commission, Central South University, Changsha, Hunan 410008; ${ }^{3}$ Department of Pathology, \\ Guangzhou Women and Children's Medical Center, Guangzhou, Guangdong 510623; \\ ${ }^{4}$ Key Laboratory of Nutrition and Metabolism, Institute for Nutritional Sciences, Chinese Academy of Sciences, \\ Shanghai 200030; ${ }^{5}$ Xiangya School of Public Health, Central South University, Changsha, Hunan 410008; \\ ${ }^{6}$ Department of Otolaryngology, Xiangya Hospital, Central South University, Changsha, Hunan 410008; \\ ${ }^{7}$ Laboratory of Cancer Precision Medicine, The First Hospital of Jilin University, Changchun, Jilin 130021, P.R. China
}

Received February 20, 2018; Accepted June 11, 2018

DOI: $10.3892 /$ ijo.2018.4462

\begin{abstract}
Resistance to radiotherapy and chemotherapy currently represents one of the major reasons for therapeutic failure in nasopharyngeal carcinoma (NPC). However, the mechanisms underlying resistance to chemotherapy in NPC remain unclear. In this study, cell counting assay, cell cycle assay and senescence associated $\beta$-galactosidase activity were performed to evaluate cell growth, proliferation and senescence, respectively. We found that the aberrant expression of cyclooxygenase-2 (COX-2) was associated with a poor outcome and recurrance in patients with NPC. In NPC cells, COX-2 overexpression increased cell proliferation, inhibited cellular senescence and resulted in chemoresistance, while the knockdown of COX-2 reduced cell proliferation, promoted cellular senescence and overcame chemoresistance. Furthermore, fibroblasts from COX-2 knockout mice exhibited cellular senescence, particularly when treated with chemotherapeutic agents. Mechanistically, COX-2 interacted with p53 protein
\end{abstract}

Correspondence to: Dr Wen Zhou, Cancer Research Institute; Key Laboratory of Carcinogenesis and Cancer Invasion, Ministry of Education; National Health and Family Planning Commission, Central South University, 110 Xiangya Road, Changsha, Hunan 410008, P.R. China

E-mail: wenzhou@csu.edu.cn

Dr Wei Li, Cancer Center, The First Hospital of Jilin University, 71 Xinmin Street, Changchun, Jilin 130021, P.R. China

E-mail: drweili@yahoo.com

Key words: cyclooxygenase-2, senescence, chemotherapy resistance, nasopharyngeal carcinoma and inhibited cellular senescence, which resulted in chemotherapeutic resistance. On the whole, these findings indicate that COX-2 may play a critical role in chemotherapeutic resistance in NPC via the inhibition of chemotherapy-induced senescence via the inactivation of $\mathrm{p} 53$. This study provides experimental evidence for the preclinical value of increasing chemotherapy-induced senescence by targeting COX-2 as an effective antitumor treatment in patients with recurrent NPC.

\section{Introduction}

Nasopharyngeal carcinoma (NPC) is a type of head and neck cancer that exhibits an endemic distribution with a high prevalence in Southern China and Southeast Asia (1,2). Clinically, approximately $70 \%$ of patients with NPC at the time of diagnosis present with locally advanced disease (3). To date, although NPC is sensitive to radiotherapy, the prognosis of NPC remains dismal, with 5-year survival rates of $34-52 \%$ (4). A major cause for this lethality is attributed to significant rates of relapse and distant metastasis following therapy (5). In this context, resistance to radiotherapy and chemotherapy represents a major challenge in the treatment of NPC $(6,7)$. Therefore, understanding the mechanisms behind therapeutic resistance in NPC is crucial.

Therapy-induced senescence occurs in response to aberrant oncogenic signaling, oxidative stress and DNA damage independent of telomere dysfunction (8-11). From either the morphological or biochemical point of view, therapy-induced senescence is highly analogous to premature senescence that has been studied in other circumstances. Recently, it has been reported that that cancer cells can undergo senescence following treatment with anticancer agents, such as doxorubicin (Dox), cisplatin (CDDP) and paclitaxel (TAX), suggesting that 
senescence may represent one of the major cellular responses to anticancer therapeutics $(12,13)$. Thus, therapy-induced senescence has been considered an indicator of the efficacy of anticancer drugs, provoking considerable interest in cancer treatment. In addition, there have been few reports regarding the role of senescence in NPC. For example, evidence indicates that CDDP induces senescence in NPC cells, resulting in cell growth arrest (14), and a high expression of SHP-1 can inhibit cellular senescence to induce radiotherapeutic resistance in NPC (15). However, the molecular mechanisms through which senescence participates in chemoresistance in NPC are poorly understood.

Cyclooxygenase $(\mathrm{COX})$ is a rate-limiting enzyme in prostaglandin biosynthesis. There are two isoforms of COX, COX-1 and COX-2. COX-1 is constitutively expressed in a number of tissues and mainly plays a role in tissue homeostasis. By contrast, COX-2 is an inducible enzyme responsible for the production of prostaglandins at sites of inflammation and wound healing (16). Of note, COX-2 is highly expressed in numerous types of human cancer, including lung, breast, ovarian, colorectal cancer and NPC (17-20). Functionally, COX-2 is thought to play a role in initiation and progression of a number of human diseases $(21,22)$ Although COX-2 has also been demonstrated to contribute to the resistance of tumor cells to conventional chemotherapy and radiotherapy, i.e., by preventing DNA damage, increasing cytokine secretion and stimulating the growth of cancer stem cells $(23,24)$, its role and mechanisms of action as regards chemotherapy-induced senescence remain largely unknown, particularly in NPC.

Therefore, understanding the mechanisms behind chemotherapeutic resistance in NPC and identifying novel therapeutic targets are required in order to improve the treatment of patients with NPC. In this study, we found that COX-2 expression was positively associated with the recurrence and a poor prognosis of patients with NPC, and we then observed the effect of COX-2 overexpression and knockdown on the proliferation and chemoresistance of NPC cells. Finally, we explored the role of COX-2 in the chemoresistance of NPC cells by inhibiting cellular senescence through the p53 pathway.

\section{Materials and methods}

Patients and primary samples. In total, 11 chronic nasopharyngitis (CN) and 43 primary NPC samples were obtained by routine diagnostic biopsy before treatment with informed consent at the Hunan Cancer Hospital (Changsha, China) between February, 2014 and January, 2015. A total of 9 paired paraffin-embedded specimens, obtained at diagnosis and recurrence respectively, were provided by the Department of Pathology of Hunan Cancer Hospital. All the specimens were examined by two independent pathologists. The Research Ethics Committee of Central South University approved our study, and all patients provided written informed consent.

Cells, antibodies and reagents. The NPC human cell lines, CNE1, CNE2, HK1 and C666-1, were cultured in RPMI-1640 medium (Gibco/Thermo Fisher Scientific, Waltham, MA, USA) with $10 \%$ fetal bovine serum (FBS) at $37^{\circ} \mathrm{C}$ in an atmosphere containing $5 \% \mathrm{CO}_{2}$. NP69, a normal nasopharyngeal epithelial cell line, was cultured in K-SFM medium (Gibco/Thermo Fisher Scientific) at $37^{\circ} \mathrm{C}$ in an atmosphere containing $5 \% \mathrm{CO}_{2}$. The mouse Lewis lung cancer (LLC) cell line was kindly provided by Professor Juanjuan Xiang at the Cancer Research Institute of Central South University, Changsha, China and cultured in Dulbecco's modified Eagle's medium (DMEM; Gibco/Thermo Fisher Scientific) with $10 \% \mathrm{FBS}$ at $37^{\circ} \mathrm{C}$ in an atmosphere containing $5 \% \mathrm{CO}_{2}$. All NPC cell lines were obtained from the Cancer Research Institute of Central South University.

Anti-COX-2 (1:1,000,\#12282) antibody was obtained from Cell Signaling Technology (Danvers, MA, USA), anti-p53 (1:200, sc-6243), anti-p21 (1:200, sc-817), anti-GAPDH $(1: 5,000$, sc-166545) and mouse or rabbit secondary antibodies were from Santa Cruz Biotechnology (Santa Cruz, CA, USA). The p53 inhibitor, Pifithrin- $\alpha$ (PFT- $\alpha$ ) powder, was purchased from Selleckchem (Houston, TX, USA) and dissolved in dimethylsulfoxide (DMSO) at $100 \mathrm{mM}$ as a stock solution. CDDP and TAX solution were purchased from Harbin Pharmaceutical Group Bio-engineering Co. (Harbin, China). The COX-2 inhibitor, NS-398 powder, was purchased from Cayman Chemical Co. (Ann Arbor, MI, USA) and dissolved in DMSO at $50 \mathrm{mg} / \mathrm{ml}$ as a stock solution.

Immunohistochemistry (IHC) and immunofluorescence (IF) staining. IHC was performed using a standard streptavidin-biotinperoxidase complex method as previously described (25). The tissue sections were incubated with anti-COX-2 antibody (1:100, \#12282; Cell Signaling Technology) overnight at $4^{\circ} \mathrm{C}$. The assessment of COX-2 staining was carried out by determining both the intensity $(0,1,2$ or 3$)$ and extent of staining $(0,0 \% ; 1,<10 \% ; 2$, $10-50 \% ; 3,>50 \%)$. Scores for the intensity and extent of staining were added to provide weighted levels of COX-2 expression.

Mouse fibroblasts on slides were fixed in $4 \%$ paraformaldehyde for $30 \mathrm{~min}$. After blocking with normal goat serum, slides were incubated overnight with primary anti-p53 antibody (1:100, sc-6243), followed by fluorescence-conjugated secondary antibodies (1:200, sc-3739) (both from Santa Cruz Biotechnology). Frozen sections of tumor tissue from LLC tumor-bearing mice were treated with anti-COX-2 antibody (1:100,\#12282; Cell Signaling Technology) as described above. The fluorescent signals were observed under an Olympus fluorescence microscope (BX43; Olympus China Co. Ltd., Beijing, China).

Stable transfection and RNA interference. The expression plasmid, pEnter-COX2, containing the open reading frame (ORF) of the $C O X-2$ gene and the control plasmid, pEnter, were purchased from Vigene Bioscience (Shandong, China). GV248 lentiviral vectors with a GFP label containing short-hairpin RNA (shRNA) targeting COX-2 (AACTGCTCAACACCGGAATTT) and a scramble sequence (TTCTCCGAACGTGTCACGT) as a control were purchased from Genechem (Shanghai, China). The CNE1 and CNE2 cells was transfected with these constructs using Lipofectamine ${ }^{\circledR} 3000$ transfection reagent (Invitrogen, Carlsbad, CA, USA) as per the manufacturer's instructions. Cells were selected using $1 \mu \mathrm{g} / \mathrm{ml}$ puromycin for 2 weeks, and stable cell lines were obtained.

Colony formation assay. A total of $1 \times 10^{3} \mathrm{CNE} 1$ cells transfected with COX-2 overexpression vector or empty vector were seeded in 6 -well plates and treated with 0.5 or $1 \mu \mathrm{g} / \mathrm{ml} \mathrm{TAX}$ and 1 or 
$2 \mu \mathrm{g} / \mathrm{ml}$ CDDP, respectively at $24 \mathrm{~h}$ after plating. Following incubation for 10 days at $37^{\circ} \mathrm{C}$ in a $5 \% \mathrm{CO}_{2}$ incubator, the cells were fixed with methanol and stained with crystal violet (Sangon Biotech, Shanghai, China) at $25^{\circ} \mathrm{C}$ for $10 \mathrm{~min}$. Colonies containing at least 50 cells were counted under an Olympus microscope (CKX53; Olympus China Co., Ltd.) with ImageJ software and colony formation ratio was calculated. Colonyforming ability was determined as the colony number/plated cell number $\mathrm{x} 100 \%$. Each experiment was repeated at least 3 times and 2 wells were used for each cell line.

Analysis of cell viability. Cell viability was assessed using the Cell Counting kit-8 (CCK-8; Bimake, Houston, TX, USA). Briefly, $1 \times 10^{3}$ cells were seeded in one well of 96-well microplates. Subsequently, $100 \mu 1$ of $10 \%$ CCK-8 solution were added to each well, and the cells were then incubated for $2 \mathrm{~h}$ at $37^{\circ} \mathrm{C}$. The absorbance at $450 \mathrm{~nm}$ was measured with an enzyme-labeled instrument (DTX880; Beckman Coulter, Brea, CA, USA) to determine cell viability. $\mathrm{IC}_{50}$ values were calculated using the following formula: Percentage inhibition $=$ (optical density value of without treatment-optical density value of test)/(optical density value of without treatment-optical density value of total inhibition). According to the fitting curve of percentage inhibition analyzed by regression analysis using SPSS 16.0 software, the $\mathrm{IC}_{50}$ values were calculated.

Cell cycle analysis. To analyze cell cycle distribution, $1 \times 10^{6}$ cells were fixed in 70\% ethanol and incubated with the Cell Cycle kit [Multisciences (Lianke) Biotech Co., Ltd., Zhejiang, China] for $30 \mathrm{~min}$. Cell cycle analysis was then carried out using flow cytometry (FACSCanto II; BD Biosciences, San Jose, CA, USA). The cell cycle phase distribution was calculated from the resultant DNA histogram using Flowjo 7 software.

Western blot and immunoprecipitation analyses. The cells were lysed using RIPA buffer (Beyotime, Shanghai, China), containing 1X Protease Inhibitor Cocktail (Selleckchem, China). Subsequently, after $30 \mathrm{~min}$ on ice and centrifugation at $4^{\circ} \mathrm{C}, 10,000 \mathrm{x} \mathrm{g}$ for $15 \mathrm{~min}$, the supernatant was collected. Protein in the supernatant was measured using a Bicinchoninic Acid Protein Assay kit (Beyotime), and the protein was denatured at $100^{\circ} \mathrm{C}$ for 10 min with $2 \mathrm{X}$ Protein Loading Buffer (Sangon Biotech). The denatured protein was then separated via $8-10 \%$ SDS polyacrylamide gel electrophoresis and transferred onto PVDF membranes (GE Healthcare Life Sciences, Little Chalfont, UK). The membranes were blocked with TBST containing $8 \%$ non-fat milk for $2 \mathrm{~h}$ at room temperature, incubated with specific primary antibodies mentioned in the reagents section at $4^{\circ} \mathrm{C}$ overnight, and then incubated with secondary antibodies labeled with horseradish peroxidase (HRP) (sc-2004 and sc-2005; Santa Cruz Biotechnology) for $1 \mathrm{~h}$. Finally, an electrochemiluminescence (ECL) system (Tanon, China) was used for detection.

Immunoprecipitation was carried out with anti-p53 (sc-6243; Santa Cruz Biotechnology) specific antibody using the Co-immunoprecipitation kit (Thermo Scientific, San Jose, CA, USA) as per the manufacturer's instructions. Rabbit IgG (CR1; Sino Biological, Beijing, China) was used as a negative control. Immunoprecipitated proteins were then detected by western blot analysis using anti-p53 and anti-COX-2 antibodies.
Analysis of senescence-associated $\beta$-galactosidase (SA- $\beta$-gal) activity. The cells were grown in 12-well plates and treated with $2 \mu \mathrm{g} / \mathrm{ml} \mathrm{CDDP}$ for $48 \mathrm{~h}$. Frozen tissue sections of lung and tumor tissue from LLC tumor-bearing mice were prepared for detection. Cellular senescence was assessed using the Senescence $\beta$-Galactosidase Staining kit (Cell Signaling Technology) as per the manufacturer's instructions. In summary, the cells were washed and fixed before staining with $\beta$-galactosidase staining solution at $37^{\circ} \mathrm{C}$ overnight. Images of the labeled cells were acquired under a BioRevo9000 microscope (Keyene, Shanghai, China) and cells with blue staining were counted in 3 different fields. The percentage of staining cells in the counted cells was used to determine the degree of cellular senescence.

Preparation of mouse fibroblasts from COX-2 knockout mice. A total of $10 \mathrm{C} 57 \mathrm{BL} / 6$ mice, 12 weeks old, weighing approximately $20 \mathrm{~g}$ with a COX-2 knockout allele were kindly provided by Dr Ying Yu (Institute for Nutritional Sciences, Shanghai, China). Fibroblasts were isolated from mouse skin and lung tissues as previously described (26). Briefly, cells were obtained through enzymatic disaggregation with $1 \mathrm{mg} / \mathrm{ml}$ collagenase for $1 \mathrm{~h}$ at $37^{\circ} \mathrm{C}$, followed by mechanical dissociation. Dissociated cells were then suspended in DMEM supplemented with $10 \%$ FBS and $100 \mathrm{U} / \mathrm{ml}$ of penicillin-streptomycin. Cells were characterized by detecting the fibroblast marker, $\alpha$-smooth muscle actin (SMA; 1:1,000, ab124964; Abcam, Cambridge, MA, USA).

Animal experiments. All animal experiments were performed in accordance with the guidelines of the Institutional Animal Care and local Veterinary Office and Ethics Committee of the Central South University (CSU), China [Animal experimental license no. LLSCC(LA) 2015-035 for Fig. 2D and LLSCC(LA) 2016-034 for Fig. 4E] under an approved protocol and the mice were maintained on a 12 day/night light cycle at $25^{\circ} \mathrm{C}$ with relative humidity of $50 \%$ and had continuous access to food and water. A total of 6 female specific pathogen-free (SPF) BALB/c nude mice obtained from Hunan SJA Laboratory Animal Co., Ltd., weighing approximately $20 \mathrm{~g}, 6-8$ weeks old were randomly allocated to 2 groups. The stably transfected cells (CNE2-Scramble and CNE2-COX- 2 sh; $\left(1 \times 10^{6}\right.$ cells per mouse) were suspended in $10 \mu$ l of RPMI serum-free medium and injected via the tail vein. Following 8 weeks of observation, two mice from the CNE2-Scramble group and one from the CNE2-COX-2 sh group exhibited a $>4 \mathrm{~g}$ loss in body weight and then all animals were sacrificed. As it is difficult to establish primary NPC tumor models in mice in the pharynx (27), we thus injected the NPC tumor cells via the tail vein and validated the effects of COX2 in the lungs. The lungs of the mice were excised for IHC analysis, using anti-COX-2 (1:100,\#12282) and anti-Ki-67 antibodies (1:100,\#9027) (both from Cell Signaling Technology) to detect protein expression

Secondly, 8 female SPF wild-type (WT) C57BL/6 mice obtained from Animal Center of the Third Hospital of Central South University, weighing approximately $18 \mathrm{~g}$ at 4 weeks of age were inoculated subcutaneously with $1 \times 10^{6}$ mouse LLC cells and then randomly allocated to 2 groups. One group of mice was treated with $100 \mu \mathrm{g} / 20 \mathrm{~g}$ body weight NS-398/PBS solution (containing 1\% DMSO) via intraperitoneal injection, 
once every 3 days for 4 weeks, while the other group of mice was treated with PBS solution (containing 1\% DMSO) as a vehicle control. Lung tissues were excised to examine senescence.

Data mining. To identify functional COX-2 in NPC, we downloaded a set of gene expression profiling data for NPC (GSE12452) from the GEO database.

Statistical analysis. Values represent the means \pm SD from at least 3 independent experiments. The significance of differences between experimental variables was determined using the Student's t-test and a Bonferroni post hoc test. Overall survival (OS) was analyzed with the log-rank method and a Kaplan Meier survival curve was drawn using GraphPad Prism 5 software. A two-sided value of $\mathrm{P}<0.05$ was considered to indicate a statistically significant difference. We downloaded a publically available gene expression profiling (GEP) database (GSE12452) and analyzed COX-2 expression in NPC.

\section{Results}

High COX-2 expression is associated with a poor survival of patients with NPC. To evaluate the significance of COX-2 in NPC pathogenesis, we analyzed the expression of COX-2 in NPC using a publically available GEP database (GSE12452). As shown in Fig. 1A, COX-2 was highly expressed at the mRNA level in the NPC tumor tissue when compared with the $\mathrm{CN}$ tissues $(\mathrm{P}<0.001)$. To validate this result, we examined the protein expression of COX-2 in paraffin-embedded sections by IHC in a cohort of $43 \mathrm{NPC}$ and $11 \mathrm{CN}$ tissues. The positive immunostaining of COX-2, primarily localized in the cytoplasm, was observed in $79 \%$ of the NPC (34/43) and $36.3 \%$ of the $\mathrm{CN}(4 / 11)$ tissues. The average staining scores in the NPC tissues were significantly higher than those in the $\mathrm{CN}$ tissues $(\mathrm{P}<0.01)$ (Fig. 1B and $\mathrm{C})$. Moreover, COX-2 expression was significantly associated with lymph node (LN) metastasis $(\mathrm{P}=0.042)$, tumor recurrence $(\mathrm{P}=0.024)$, and mortality $(\mathrm{P}=0.044)$ (Table I). Of note, the patients with NPC with a high COX-2 expression had a markedly shorter OS (median OS, 60.5 months) than those with a low COX-2 expression (median OS, >160 months; $\mathrm{P}=0.038$ ) (Fig. 1D). A comparison was then made for each of the 9 paired samples obtained at diagnosis and recurrence; $\mathrm{COX}-2$ expression was markedly increased after recurrence $(\mathrm{P}<0.01)$ (Fig. $1 \mathrm{E}$ and $\mathrm{F})$. Taken together, these results suggest that COX-2 plays an important role in the pathogenesis of NPC, as well as in disease progression (e.g., metastasis) and recurrence.

COX-2 knockdown attenuates the proliferation of NPC cells in vitro and in vivo. To explore the functional role of $\mathrm{COX}-2$ in NPC, we detected the protein expression of COX-2 in NPC cell lines and the NP69 normal cell line. The results of western blot analysis revealed that the protein level of COX-2 was clearly higher in the NPC cell lines than in the normal NP69 cells. Based on this observation, the CNE1 cells with a lower COX-2 expression and the CNE2 cells with a higher COX-2 expression were employed for use in the following experiments to elucidate the function of COX-2 in NPC. COX-2 was overexpressed in the CNE1 cells that displayed a low basal level of COX-2,
Table I. Association between COX-2 expression and clinical characteristics of patients with NPC.

\begin{tabular}{lccc}
\hline & \multicolumn{2}{c}{ COX-2 } & \\
\cline { 2 - 3 } Characteristics & High (n, \%) & Low (n, \%) & P-value \\
\hline Sex & & & 0.782 \\
Male (28) & $10(35.7)$ & $18(64.3)$ & \\
Female (15) & $6(40)$ & $9(60)$ & \\
Age, years & & & 0.834 \\
$<50$ (26) & $10(38.4)$ & $16(61.6)$ & \\
$\geq 50(17)$ & $6(35.2)$ & $11(64.8)$ & \\
Clinical stage & & & 0.744 \\
I-II (12) & $4(33.3)$ & $8(66.7)$ & \\
III-IV (31) & $12(38.7)$ & $19(61.3)$ & \\
LMN status & & & $0.042^{\mathrm{a}}$ \\
No LMN (6) & $0(0)$ & $6(100)$ & \\
LMN (37) & $16(43.2)$ & $21(56.8)$ & \\
Recurrence & & & $0.024^{\mathrm{a}}$ \\
No (28) & $7(25)$ & $21(75)$ & \\
Yes (15) & $9(60)$ & $6(40)$ & \\
Survival status & & $10(47.7)$ & \\
Alive (22) & $5(22.7)$ & $17(77.3)$ & \\
Deceased (21) & $11(52.3)$ & $1044^{\mathrm{a}}$ \\
\hline
\end{tabular}

andicates a statistically significant difference $(\mathrm{P}<0.05)$ as determined by the Chi-square test. NPC, nasopharyngeal carcinoma; COX-2, cyclooxygenase-2; LMN, lymph node metastasis.

while it was knocked down by shRNA in both the CNE1 and CNE2 cells (Fig. 2A). The results of CCK-8 assay revealed that the downregulation of COX-2 using shRNA in either the CNE2 (CNE2-COX-2 sh) or CNE1 (CNE1-COX-2 sh) cells markedly inhibited cell proliferation, compared to the scramble control (left and middle panels; $\mathrm{P}<0.01$ for each case, Fig. 2B). By contrast, COX-2 overexpression in the CNE1 cells (CNE1-COX-2 OE) markedly increased the cell proliferation rate, compared to the empty vector (CNE1-EV) control (right panel; $\mathrm{P}<0.01$, Fig. $2 \mathrm{~B}$ ). In this context, the knockdown of COX-2 in the CNE2 or CNE1 cells also resulted in cell cycle arrest at the G0/G1 phase $(\mathrm{P}<0.05$, Fig. $2 \mathrm{C})$. To validate the effects of COX-2 knockdown on NPC tumor growth and metastasis to lung in vivo, CNE2-Scramble and CNE2-COX-2 sh cells were injected via the tail vein into nude mice ( $\mathrm{n}=3$ for each group, Fig. 2D). Furthermore, the number of tumor nodules in the lung tissues from the mice in the CNE2-Scramble group was greater than that from the mice in the CNE2-COX-2 sh group at 8 weeks after inoculation $(\mathrm{P}<0.05,15.3 \pm 1.7$ vs. $4.7 \pm 1.7$, Fig. $2 \mathrm{E}$ and $\mathrm{F})$. As shown in Fig. 2G, IHC staining revealed a marked decrease in the number of Ki-67-positive cells in the tumor nodules derived from the CNE2-COX-2 sh group cells, when compared to those from the CNE2-Scramble group cells. Taken together, these results indicate that COX-2 knockdown attenuates the proliferation of NPC cells in vitro and in vivo. 

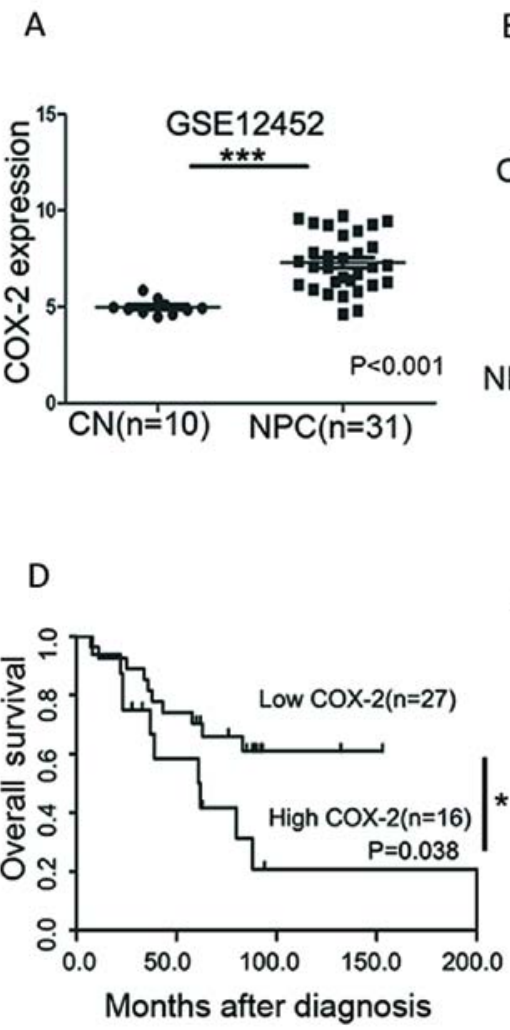
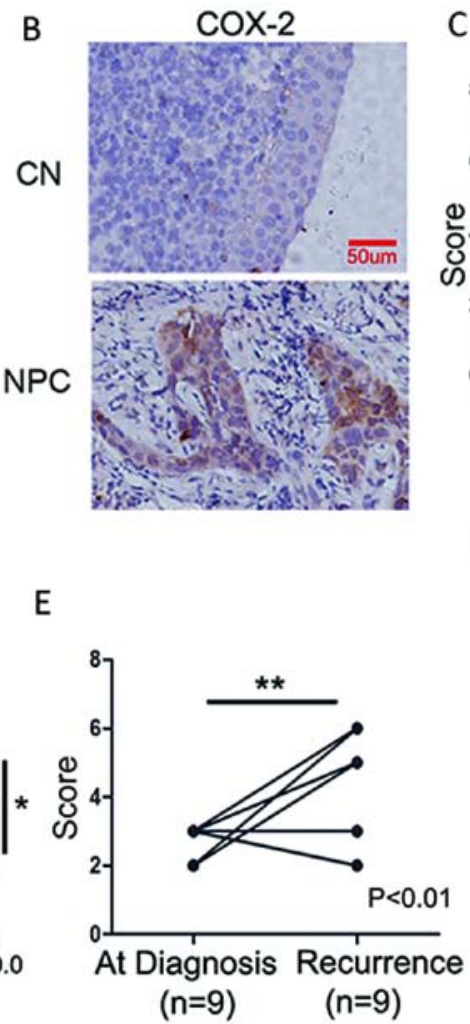

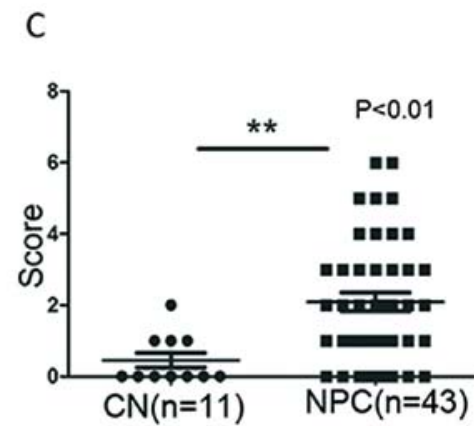

F

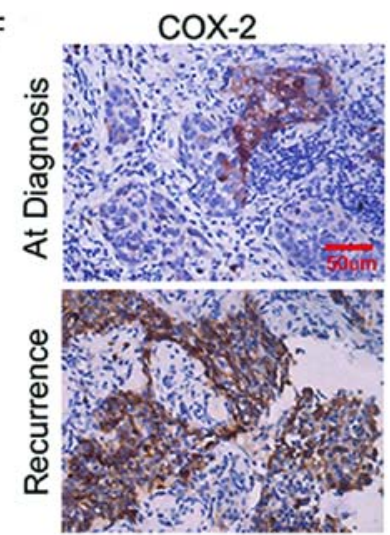

Figure 1. A high COX-2 expression is associated with a poor survival in NPC. (A) Comparison of COX-2 expression between NPC and CN tissues using the publically-available GEP datasets. (B) Representative images of IHC staining for COX-2 expression in NPC and CN tissue sections. (C) Analysis of COX-2 expression by IHC in a cohort of 43 NPC tissues compared to CN tissues ( $n=11)$ by the Student's t-test. (D) Effect of COX-2 expression on the overall survival (OS) of patients with NPC ( $\mathrm{n}=43$ ) by Kaplan-Meier analysis with the log-rank test. (E) Comparison of COX-2 expression in paired NPC tumor samples ( $\mathrm{n}=9$ ) by a paired Student's t-test. (F) Representative images of IHC staining for COX-2 expression in paired NPC tumor samples at diagnosis and recurrence. COX-2, cyclooxygenase-2, NPC, nasopharyngeal carcinoma; $\mathrm{CN}$, chronic nasopharyngitis.

High COX-2 expression increases chemoresistance in NPC cells. To explore the association between the expression of COX-2 and chemotherapeutic resistance, cell viability and colony formation ability were analyzed by CCK- 8 and colony formation assays, respectively in the CNE1 cells overexpressing COX-2 followed by CDDP or TAX treatment. Compared to the control cells, the numbers of viable CNE1 and CNE2 cells in which COX-2 was knocked down were markedly reduced following CDDP or TAX treatment, while the numbers of viable CNE1 cells overexpressing COX-2 were significantly higher than those of the control cells $(\mathrm{P}<0.05$ for each case, compared to the scramble or EV controls, Fig. 3A and B). Moreover, the results of colony formation assay revealed a significant increase in the colony-forming ability of the CNE1 cells overexpressing COX-2, compared to the EV control ( $36 \pm 1.2$ vs. $18.25 \pm 0.9 \%$, $\mathrm{P}<0.05$, Fig. 3C). Following treatment with CDDP, COX-2 overexpression reduced the lethality of the agent at the two tested doses (3.0-fold, $13.35 \pm 0.7$ vs. $4.41 \pm 0.6 \%$ and 1.6 -fold, $5.65 \pm 0.8$ vs. $3.38 \pm 0.4 \%$ for the EV control treated with 1 and $2 \mu \mathrm{g} / \mathrm{ml}$ CDDP, respectively, Fig. 3C). Following treatment with TAX, COX-2 overexpression reduced the lethality of the agent at two tested doses (2.5-fold, $15.02 \pm 0.7$ vs. $6.08 \pm 0.6 \%$ and 4.8 -fold, $5.68 \pm 1.4$ vs. $1.16 \pm 0.2 \%$ for the EV control treated with 0.5 and $1 \mu \mathrm{g} / \mathrm{ml}$ TAX; $\mathrm{P}<0.05$ for each case, respectively, Fig. 3C). Above all, these results demonstrate that COX-2 expression leads to NPC cell chemoresistance.
Inhibition of COX-2 increases chemotherapy-induced senescence in vitro and in vivo. In order to elucidate the mechanisms underlying COX-2-mediated resistance to chemotherapeutic agents, the role of COX-2 in cellular senescence induced by chemotherapy was evaluated following treatment with various concentrations of CDDP. The results of SA- $\beta$-gal (28) assay revealed that $\mathrm{COX}-2$ overexpression reduced the percentage of $\beta$-galactosidase-positive (blue) senescent CNE1 cells ( $2.5 \pm 0.3$ vs. $4.8 \pm 0.3 \%$; $\mathrm{P}<0.01$, Fig. $4 \mathrm{~A})$, while the knockdown of COX-2 with shRNA increased the percentage of senescent cells $(14 \pm 1$ vs. $5.4 \pm 0.2 \%$; $\mathrm{P}<0.01$, Fig. $4 \mathrm{~B})$. Notably, whereas exposure to CDDP induced a marked increase in the number of senescent cells, this event was diminished by COX-2 overexpression ( $12 \pm 0.3$ vs. $21 \pm 0.2 \%$; $\mathrm{P}<0.01$, Fig. $4 \mathrm{~A})$. By contrast, exposure to CDDP induced a further increase in the number of senescent cells in the CNE1 cells in which COX-2 was knocked down $(31 \pm 1$ vs. $18.3 \pm 0.3 \%$; $\mathrm{P}<0.01$, Fig. $4 \mathrm{~B})$.

Previous studies have suggested that fibroblasts are a valuable tool for studying cellular senescence (29). Thus, in this study, to further validate the functional role of COX-2 in cellular senescence, fibroblasts without $\mathrm{COX}-2$ expression were obtained from COX-2 knockout (COX-2 $2^{-/}$) mice (30) (Fig. 4C). As shown in Fig. 4D, the number of SA- $\beta$-gal-positive cells increased in both the lung ( $8.9 \pm 1$ vs. $5.2 \pm 0.3 \%$ for WT) and skin fibroblasts $(9.2 \pm 0.6$ vs. $4.1 \pm 0.6 \%$ for WT) from the $\mathrm{COX}-2^{-/-}$mice $(\mathrm{P}<0.01$ for both cases). Additionally, COX-2 gene knockout promoted the senescence induced by CDDP, 
A

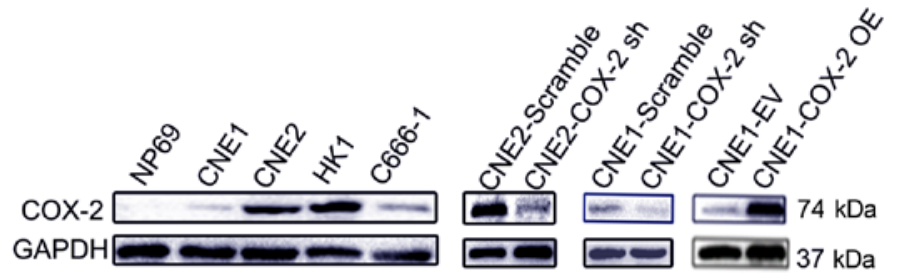

B
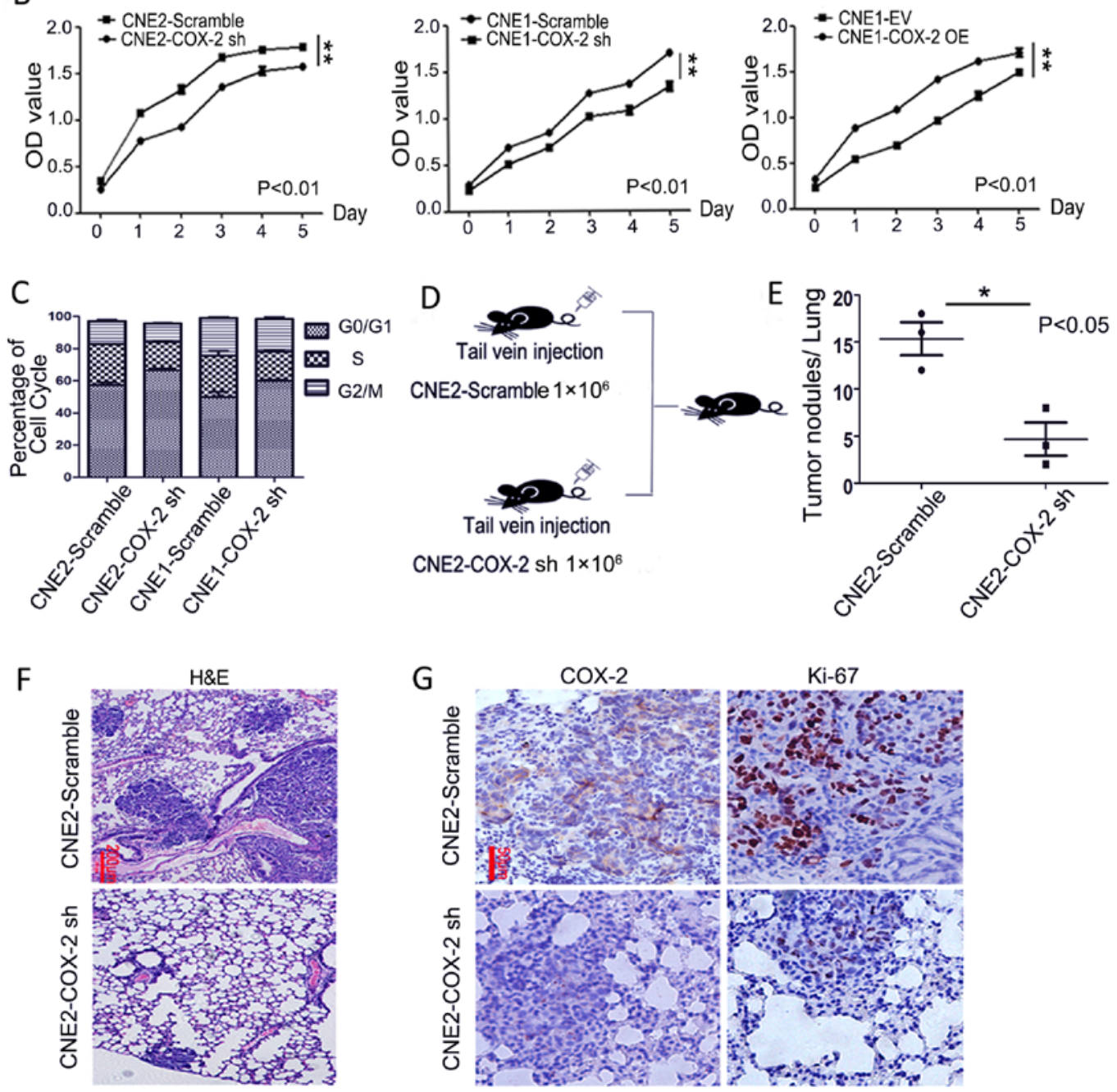

Figure 2. COX-2 knockdown attenuates the proliferation of NPC cells in vitro and in vivo. (A) COX-2 expression in 4 human NPC cell lines, the NP69 normal cell line and in NPC cells in which COX-2 was downregulated or overexpressed. (B) Cell viability analysis of CNE2-Scramble vs. CNE2-COX-2 sh, CNE1-Scramble vs. CNE1-COX-2 sh and CNE1-EV vs. CNE1-COX-2 OE cells. Values represent the means \pm SD from at least 3 independent experiments. (C) Cell cycle analysis of CNE2-Scramble vs. CNE2-COX-2 sh, and CNE1-Scramble and CNE1-COX-2 sh cells. Values represent the means \pm SD from at least 3 independent experiments. (D) Schematic diagram of mice inoculated with CNE2-Scramble and CNE2-COX-2 sh cells via the tail vein. (E) Analysis of tumor nodules in lungs of mice inoculated with CNE2-Scramble and CNE2-COX-2 sh cells. (F and G) H\&E staining and IHC staining for COX-2 and Ki-67 expression in tumor tissues from lungs of mice inoculated with CNE2-Scramble and CNE2-COX-2 sh cells. COX-2, cyclooxygenase-2; NPC, nasopharyngeal carcinoma.

as reflected by the increased number of SA- $\beta$-gal-positive cells, in the lung $(29.2 \pm 0.2$ vs. $15.2 \pm 0.3 \%$ for WT) and skin fibroblasts $(36.5 \pm 0.2$ vs. $17.6 \pm 0.3 \%$ for WT; $\mathrm{P}<0.01$ for each case, Fig. 4D). As shown in Fig. 4D that the numbers of SA- $\beta$-gal-positive cells were increased in fibroblasts from COX $-2^{--}$mice (C57BL/6 background), which suggested that senescence was induced in the COX-2-/- mouse model, this prompted us to investigate the role of senescence in the mice with the same genetic C57BL/6 background following treatment with NS-398. As the LLC cell lines can lead to tumor bearing C57BL/6 WT mice (31), while none of the NPC cell lines could, we selected the LLC line for use in this in vivo experiment. The COX-2 inhibitor, NS-398, was employed in the mouse model established by subcutaneous inoculation with $1 \times 10^{6}$ LLC cells into C57BL/6 mouse (Fig. 4E). The results suggested that the administration of NS-398 inhibited tumor growth, compared to the vehicle control $(\mathrm{P}<0.05, \mathrm{n}=4$ for each group, Fig. 4F). Moreover, the number of senescent cells increased in the lungs from LLC tumor-bearing mice treated with NS-398 ( $\mathrm{P}<0.01,12 \pm 1.7$ vs. $3.3 \pm 0.8 \%$, compared to the vehicle control, Fig. 4G). In addition, COX-2 expression was weaker in the tumor tissue from the LLC tumor-bearing 
A
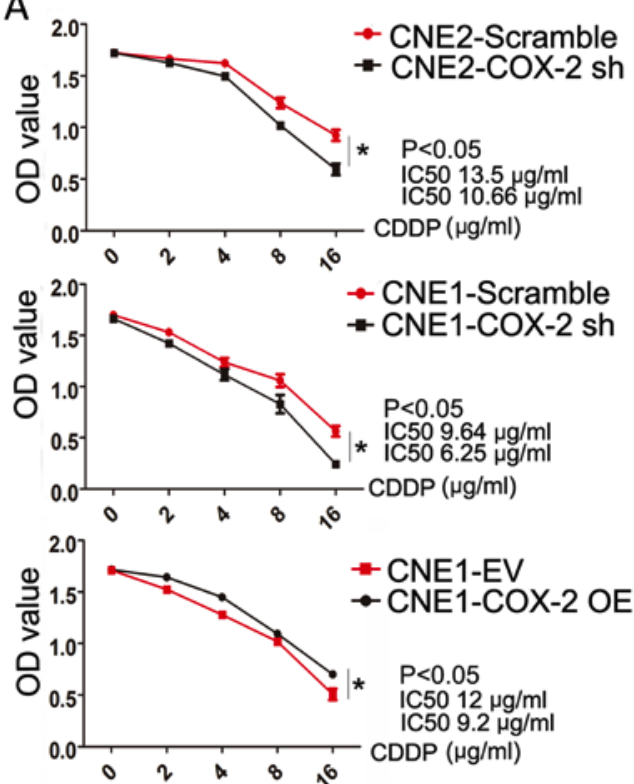
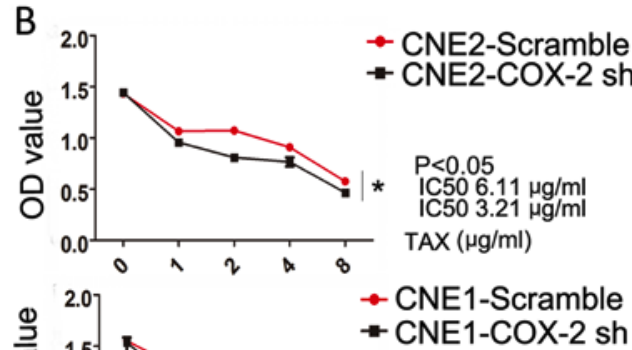

$\rightarrow$ CNE1-COX-2 sh
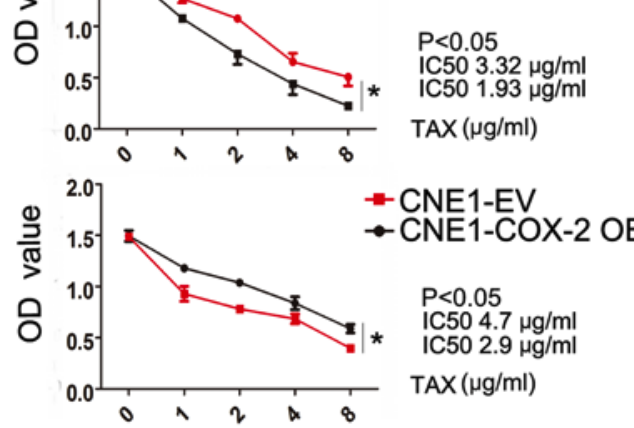

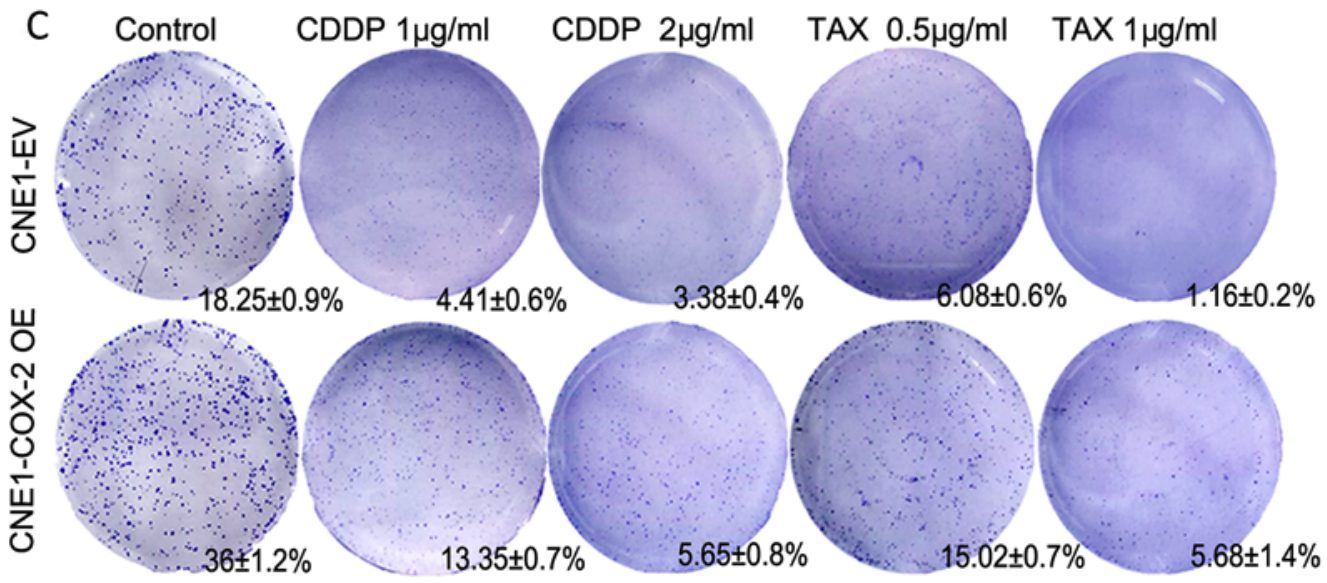

Figure 3. A high COX-2 expression enhances the chemoresistance of NPC cells. (A) Analysis of cell viability by CCK-8 assay in CNE2-Scramble vs. CNE2-COX-2 sh, CNE1-Scramble vs. CNE1-COX-2 sh and CNE1-EV vs. CNE1-COX-2 OE cells following treatment with a series of concentrations of CDDP for 48 h. Values represent the means \pm SD for at least three independent experiments. (B) Analysis of cell viability by CCK-8 assay in CNE2-Scramble vs. CNE2-COX-2 sh, CNE1-Scramble vs. CNE1-COX-2 sh and CNE1-EV vs. CNE1-COX-2 OE cells following treatment with a series of concentrations of TAX for 48 h. Values represent the means \pm SD from at least 3 independent experiments. (C) Analysis of colony formation of CNE1-EV vs. CNE1-COX-2 OE cells following treatment with CDDP and TAX. Values represent the means \pm SD from at least 3 independent experiments. COX-2, cyclooxygenase-2; CDDP, cisplatin; TAX, paclitaxel.

mice treated with NS-398 (Fig. 4H). SA- $\beta$-gal staining revealed that the number of senescent cells increased in the tumor tissue from the mice treated with NS-398 $(\mathrm{P}<0.01$, $10 \pm 2$ vs. $1.8 \pm 0.2 \%$, compared to the vehicle control, Fig. $4 \mathrm{I}$ ). Thus, these results support the notion that COX-2 negatively regulates cellular senescence and that $\mathrm{COX}-2$ may serve as a potential target for the further clinical treatment of NPC.

COX-2 interacts with p53 to inhibit therapy-induced senescence. It is well established that p53 plays a critical role in cellular senescence (8). Thus, in this study, to determine whether p53 is also involved in the COX-2-mediated inhibition of senescence, the association between COX-2 and p53 expression in NPC cells was investigated. Although the expression of p53 exhibited no distinct change in the CNE1-Scramble and CNE1-COX-2 sh cells, downstream p21 expression was upregulated (Fig. 5A). In addition, we found that p53 expression was markedly upregulated in the nuclei of $\mathrm{COX}-2^{-/}$skin fibroblasts, compared to those from WT mice (Fig. 5B), suggesting that p53 may play its role mainly through entering the nucleus when COX-2 is downregulated. Furthermore, co-immunoprecipitation assay revealed that $\mathrm{COX}-2$ was precipitated with $\mathrm{p} 53$ in he CNE1 cells overexpressing COX-2 with or without exposure to $2 \mu \mathrm{g} / \mathrm{ml} \mathrm{CDDP}$ (Fig. 5C), consistent with a previous finding that COX-2 interacts with p53 in the nucleus (32). Then, we examined whether inhibiting p53 would affect the function of COX-2 in senescence. As shown in Fig. 5D, the knockdown of the expression of COX-2 promoted senescence in the CNE1 cells $(13.8 \pm 0.6$ vs. $3.9 \pm 0.3 \%$ for the scramble control, $\mathrm{P}<0.01)$; CDDP induced a further increase in the number of senescent cells $(32.1 \pm 0.3$ vs. $13.8 \pm 0.6 \%$ for the untreated control, $\mathrm{P}<0.01)$. Notably, increased senescence in the CNE1-COX-2 sh cells was significantly blocked by the p53 inhibitor, PFT- $\alpha$ (5.2 \pm 0.3 vs. $13.8 \pm 0.6 \%$ for untreated control or vs. $32.1 \pm 0.3 \%$ for CDDP alone, $\mathrm{P}<0.01$ for both cases, Fig. 5D). Taken together, these findings support a notion that COX-2 inhibits 
A
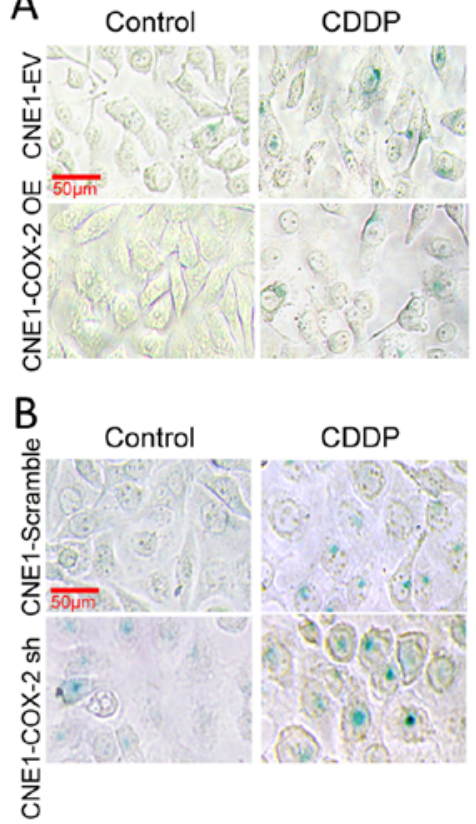

岁
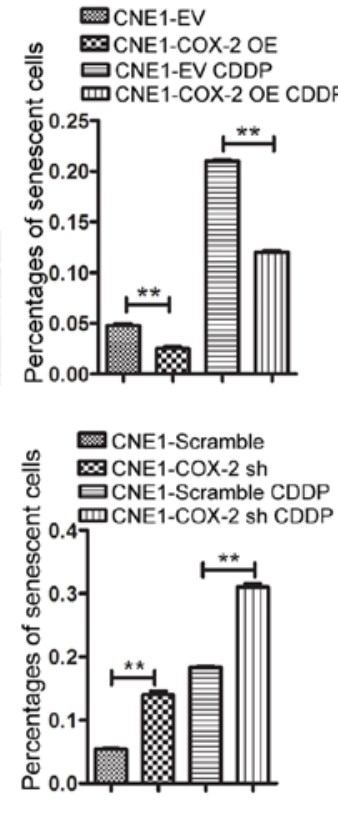

D

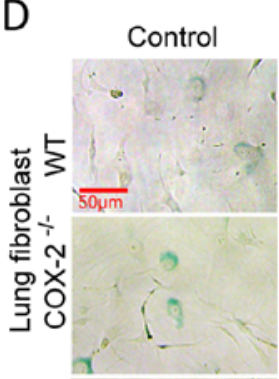

CDDP
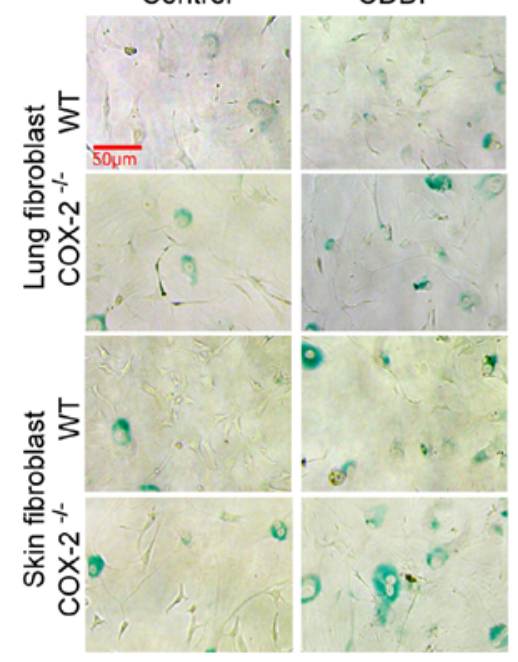

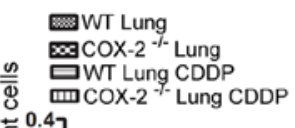

0.4

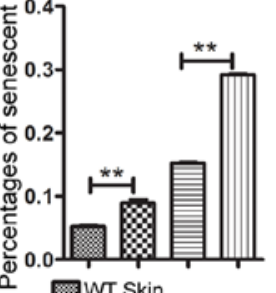

Q $\mathrm{m}$ WT Skin

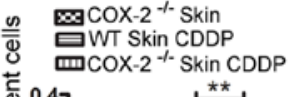

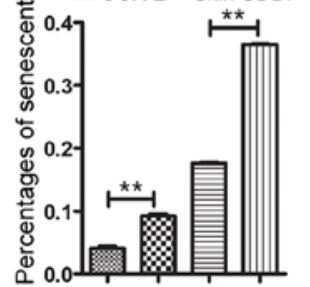

G Lung B-gal
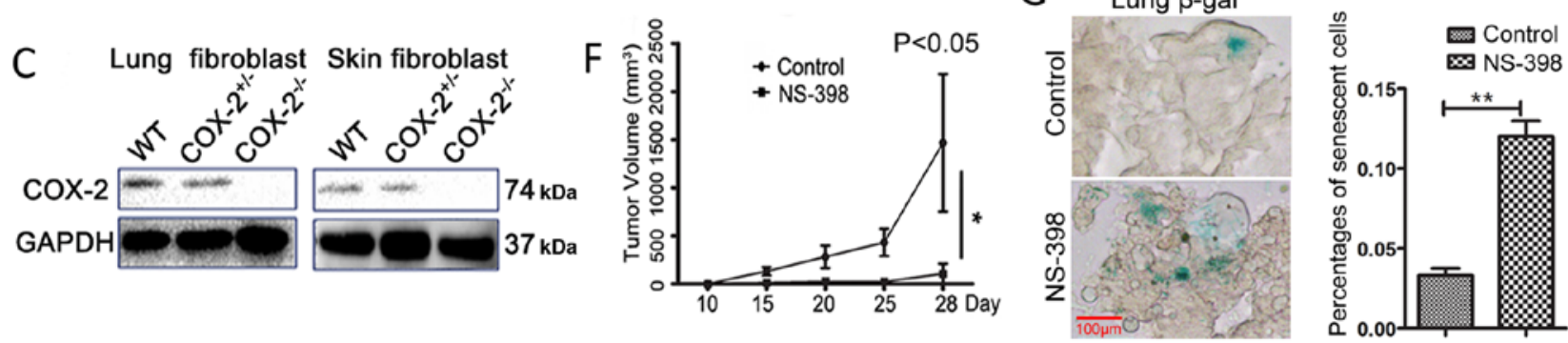

$\mathrm{E}$

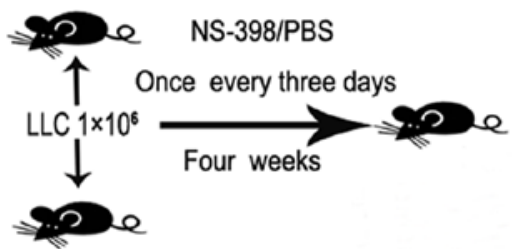

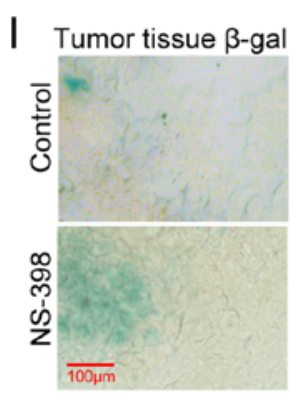

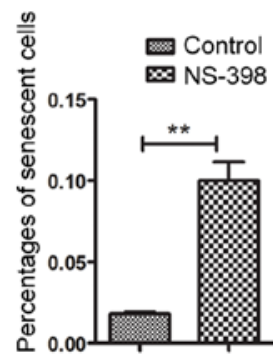

Figure 4. Inhibition of COX-2 increases chemotherapy-induced senescence in vitro and in vivo. (A) Analysis of senescence by SA- $\beta$-gal activity in CNE-EV vs. CNE1-COX-2 OE cells following treatment with or without $2 \mu \mathrm{g} / \mathrm{ml}$ CDDP. Values represent the means \pm SD from at least 3 independent experiments. (B) Analysis of senescence by SA- $\beta$-gal activity in CNE1-Scramble vs. CNE1-COX-2 sh cells following treatment with or without $2 \mu \mathrm{g} / \mathrm{ml}$ CDDP. Values represent the means \pm SD from at least 3 independent experiments. (C) Western blot analysis of COX-2 expression in fibroblasts isolated from lung and skin tissues of COX-2 knockout (COX-2- $)$ and littermate wild-type (WT) mice. (D) Analysis of SA- $\beta$-gal activity in fibroblasts from lung and skin tissues of $\mathrm{COX}-2^{-/}$and WT mice treated with or without $2 \mu \mathrm{g} / \mathrm{ml}$ CDDP. Values represent the means \pm SD for at least three independent experiments. (E) Schematic diagram of the establishment of an LLC tumor-bearing mouse model using C57BL/6 mice and the administration of $100 \mu \mathrm{g} / 20 \mathrm{~g}$ NS-398/PBS solution (containing $1 \%$ DMSO) (PBS containing 1\% DMSO as the vehicle control). (F) Analysis of tumor volumes in LLC tumor-bearing mice treated with/without $100 \mu \mathrm{g} / 20 \mathrm{~g}$ NS-398. (G) Analysis of SA- $\beta$-gal activity in frozen tissue sections of lungs from LLC tumor-bearing mice treated with/without $100 \mu \mathrm{g} / 20 \mathrm{~g}$ NS-398. (H) Immunofluorescence analysis of COX-2 expression in tumor tissue from tumor-bearing mice treated with/without $100 \mu \mathrm{g} / 20 \mathrm{~g}$ NS-398. (I) Analysis of SA- $\beta$-gal activity in frozen tissue sections of tumor tissue from LLC tumor-bearing mice treated with/without $100 \mu \mathrm{g} / 20 \mathrm{~g}$ NS-398. COX-2, cyclooxygenase-2; CDDP, cisplatin; SA- $\beta$-gal, senescence-associated $\beta$-galactosidase. ${ }^{*} \mathrm{P}<0.05$ and ${ }^{* *} \mathrm{P}<0.01$ indicate statistically significant differences.

chemotherapy-induced senescence in NPC cells, likely via binding p53 and inactivating p53 function.

\section{Discussion}

The standard care for patients with locally advanced NPC currently includes neoadjuvant chemotherapy combined with radiotherapy. However, therapeutic resistance remains the most important challenge in clinical practice. Inflammatory factors, such as interleukin (IL)- 6 and tumor necrosis factor (TNF) $\alpha$ not only precede the development of NPC, but are also associated with a poor survival of patients with NPC $(33,34)$. In this study, we found that the pro-inflammatory mediator, COX-2, was expressed in NPC patient tissues at diagnosis and 
A

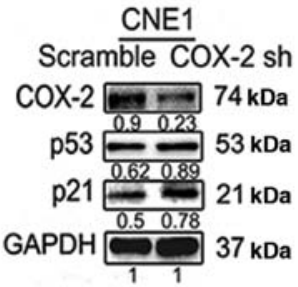

B

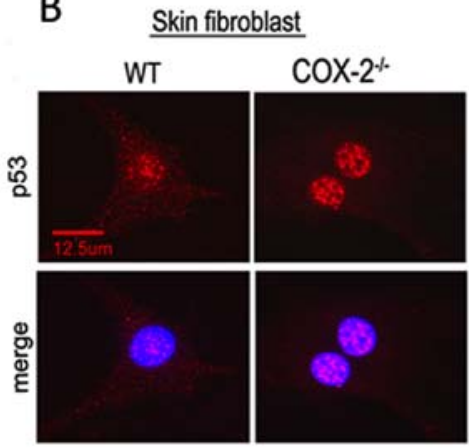

C

CNE1-COX-2 OE

Control CDDP $48 \mathrm{~h}$

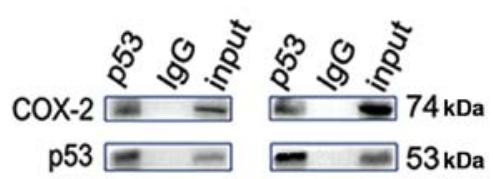

D CNE1-Scramble CNE1-COX-2 sh
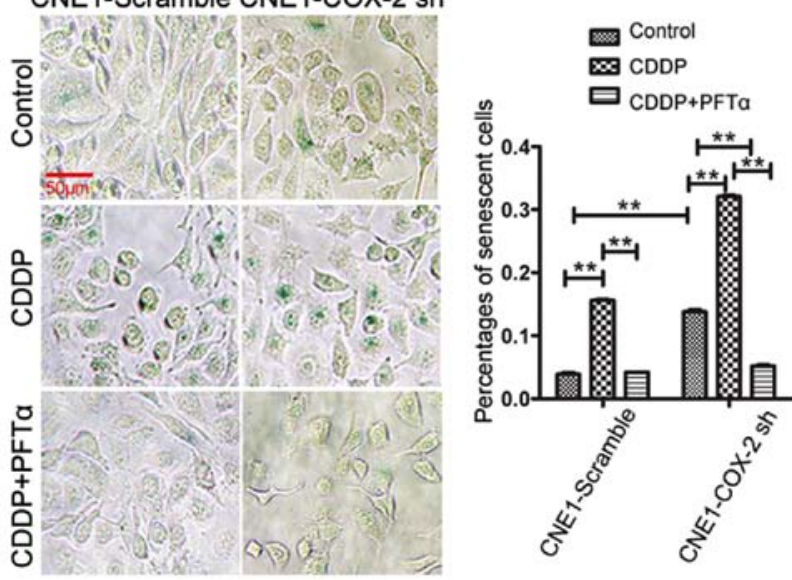

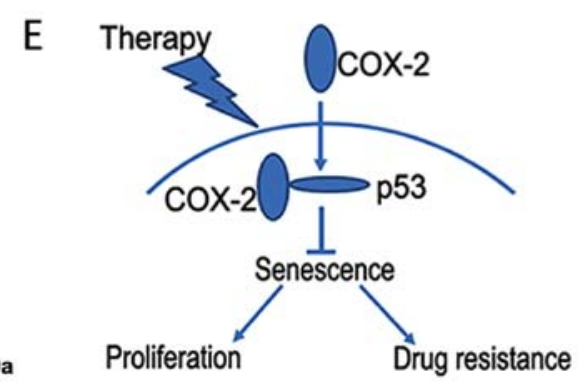

Figure 5. COX-2 interacts with p53 to inhibit therapy-induced senescence. (A) Western blot analysis of the expression of COX-2, p53 and p21 in CNE1-Scramble and CNE1-COX-2 sh cells. (B) Immunofluorescence analysis of p53 expression in fibroblasts from skin tissues of COX-2 ${ }^{-/}$and wild-type (WT) mice. (C) Co-immunoprecipitation analysis of COX-2 and p53 interaction in CNE1-COX-2 OE cells with or without treatment with CDDP. (D) Analysis of SA- $\beta$-gal activity in CNE1-Scramble vs. CNE1-COX-2 sh cells following treatment with CDDP in the presence or absence of PFT- $\alpha$. Values represent the means \pm SD from at least 3 independent experiments. (E) A working model illustrating that COX-2 promotes tumor cell proliferation and inhibits therapy-induced cellular senescence by interacting with p53 in NPC. COX-2, cyclooxygenase-2; NPC, nasopharyngeal carcinoma; CDDP, cisplatin; SA- $\beta$-gal, senescence-associated $\beta$-galactosidase; PFT- $\alpha$, pifithrin- $\alpha{ }^{* *} \mathrm{P}<0.01$, indicate statistically significant differences.

also highly expressed in paired patients with recurrent NPC, which suggested that COX-2 promotes NPC tumorigenesis and recurrence. In addition, we identified the functional role of COX-2 in the pathogenesis of NPC and unveiled the underlying mechanisms of COX-2-mediated chemoresistance via the inhibition of chemotherapy-induced senescence in NPC. Moreover, we also found that cellular senescence significantly increased in fibroblasts from COX-2 knockout mice, particularly when treated with CDDP. This study describes for the first time, to the best of our knowledge, that COX-2 gene knockout promotes senescence in a mouse model.

Therapeutic resistance includes intrinsic and acquired resistance. Acquired resistance develops during treatment often through the activation of alternative compensatory signaling pathways that lead to the evasion of cell death. COX-2 may contribute to the repopulation of tumors from cancer stem cells and the activation of cancer-related genes, which contributes to acquired resistance (35). Of note, cellular senescence acts as a double-edged sword in the pathogenesis and treatment of cancer (8). On the one hand, some senescent tumor cells can bypass the cell cycle restriction and thereby survive from therapy. On the other hand, therapy-induced senescence can suppress tumor growth by irreversibly arresting cell proliferation. For instance, Braumüller et al reported that IFN- $\gamma$ and TNF induced senescence in numerous murine and human cancers, and that this may be a general mechanism for arresting cancer progression (36). Goel et al also demonstrated that CDK4/6 inhibitors overcame therapeutic resistance in HER2-positive breast cancer by increasing G1 arrest and cellular senescence through the suppression of $\mathrm{Rb}$ phosphorylation (37). In this study, we found that chemotherapy induced cellular senescence in NPC cells, while the senescence induced by the inhibition of COX-2 may confer acquired therapeutic resistance.

To date, there are few studies available reporting the function of COX-2 in the regulation of cellular senescence. Furthermore, the role of COX-2 in therapy-induced senescence remains almost unknown. Under physiological conditions, the inhibition of prostaglandin $\mathrm{E}_{2}\left(\mathrm{PGE}_{2}\right)$ production has been shown to be therapeutically beneficial in the treatment of age-associated collagen deficits in human skin (38). Kim et al found that p16 and p53 expression levels were upregulated in the tissues of COX-2 transgenic mice, suggesting that an increased COX-2 expression has an impact on the aging process (39). However, Han et al observed that mouse lung fibroblasts (MLFs) derived from lung tissues expressed less p21 in adult WT mice than in COX-2 knockout mice. They also found that $\mathrm{p} 53$-induced COX-2 expression counteracted the apoptosis mediated by p53 (40). In the present study, we observed that COX- 2 could bind to $\mathrm{p} 53$ protein, as determined 
by co-immunoprecipitation; however, it did not influence the protein expression of $\mathrm{p} 53$, while the $\mathrm{p} 53$ protein level was increased in the nuclei of fibroblasts from COX-2 knockout mice. This suggested that COX-2 may play a negative role in the regulation of senescence in NPC cells, particularly induced by chemotherapy, mostly likely via the inactivation of p53.

It should be noted that this study was partly based on the use of CNE-1 and CNE-2 cells to investigate senescence in NPC. These have been demonstrated to be contaminated with HeLa cell line, and this may be a potential limitation of this study (41).

In conclusion, the results of the present study indicate that a high expression of $\mathrm{COX}-2$ is associated with the recurrence and a poor prognosis of patients with NPC, and that COX-2 expression confers chemotherapeutic resistance in NPC. Mechanistically, COX-2 functions to promote chemotherapeutic resistance, mainly through the inhibition of senescence by interacting with and inactivating p53 in NPC cells. Based on these findings, we propose a working model for the mechanisms of action of COX-2 in NPC, as shown in Fig. 5E. It is suggested that COX-2 may serve as a potential predictor of the recurrence and therapeutic resistance, and may serve as a therapeutic target for the development of targeted therapy to eradicate resistant tumor cells in the treatment of NPC.

\section{Acknowledgements}

The authors appreciate the discussions provided by all the members in the laboratory of WZ.

\section{Funding}

This study was supported by grants from the National Natural Science Foundation of China (NSFC; nos. 81570205, 81400169, 81672993 and 81471165), the Strategic Priority Research Program of Central South University (no. ZLXD2017004), and the Hunan Province Natural Science Foundation of China (HNSF; no. 2015JJ2158).

\section{Availability of data and materials}

All data generated or analyzed during this study are included in this published article.

\section{Authors' contributions}

WZ, FJ, WL and CS designed research. WZ, CS, YG, JG, XF, LZ, XZ, GuangchengL, WJ, YD and GuiyuanL analyzed and interpreted the data. CS, YL, JL, HX, YZ and GuizhuL performed the experiments. WZ, CS and YD wrote the manuscript.

\section{Ethics approval and consent to participate}

For the use of human samples, the Research Ethics Committee of Central South University approved our study, and all patients provided written informed consent. All animal experiments were performed in accordance with the guidelines of the Institutional Animal Care and local Veterinary Office and Ethics Committee of the Central South University, China
[Animal experimental license no. LLSCC(LA) 2015-035 for Fig. 2D and LLSCC(LA) 2016-034 for Fig. 4E].

\section{Patient consent for publication}

Not applicable.

\section{Competing interests}

The authors declare that they have no competing interests.

\section{References}

1. Ma BB, Hui EP and Chan AT: Investigational drugs for nasopharyngeal carcinoma. Expert Opin Investig Drugs 26: 677-685, 2017.

2. Torre LA, Bray F, Siegel RL, Ferlay J, Lortet-Tieulent J and Jemal A: Global cancer statistics, 2012. CA Cancer J Clin 65: 87-108, 2015.

3. Chua ML, Wee JT, Hui EP and Chan AT: Nasopharyngeal carcinoma. Lancet 387: 1012-1024, 2016.

4. Shao JY, Wang HY, Huang XM, Feng QS, Huang P, Feng BJ, Huang LX, Yu XJ, Li JT, Hu LF, et al: Genome-wide allelotype analysis of sporadic primary nasopharyngeal carcinoma from southern China. Int J Oncol 17: 1267-1275, 2000.

5. Chan AT: Current treatment of nasopharyngeal carcinoma. Eur J Cancer 47 (Suppl 3): S302-S303, 2011.

6. Chan AT, Grégoire V, Lefebvre JL, Licitra L, Hui EP, Leung SF and Felip E; EHNS-ESMO-ESTRO Guidelines Working Group: Nasopharyngeal cancer: EHNS-ESMO-ESTRO Clinical Practice Guidelines for diagnosis, treatment and follow-up. Ann Oncol 23 (Suppl 7): vii83-vii85, 2012.

7. Chen C, Chen T, Huang C, Wang J and Fei Z: Experience of weekly cisplatin concurrent with intensity-modulated radiotherapy for locally advanced nasopharyngeal carcinoma patients with resistance to neoadjuvant chemotherapy. Medicine (Baltimore) 96: e8434, 2017.

8. Ewald JA, Desotelle JA, Wilding G and Jarrard DF: Therapyinduced senescence in cancer. J Natl Cancer Inst 102: 1536-1546, 2010.

9. Soto-Gamez A and Demaria M: Therapeutic interventions for aging: The case of cellular senescence. Drug Discov Today 22: 786-795, 2017.

10. Loaiza N and Demaria M: Cellular senescence and tumor promotion: Is aging the key? Biochim Biophys Acta 1865: 155-167, 2016.

11. Lee $M$ and Lee JS: Exploiting tumor cell senescence in anticancer therapy. BMB Rep 47: 51-59, 2014.

12. Gordon RR and Nelson PS: Cellular senescence and cancer chemotherapy resistance. Drug Resist Updat 15: 123-131, 2012.

13. Petrova NV, Velichko AK, Razin SV and Kantidze OL: Small molecule compounds that induce cellular senescence. Aging Cell 15: 999-1017, 2016.

14. Wang X, Wong SC, Pan J, Tsao SW, Fung KH, Kwong DL, Sham JS and Nicholls JM: Evidence of cisplatin-induced senescent-like growth arrest in nasopharyngeal carcinoma cells. Cancer Res 58: 5019-5022, 1998.

15. Sun Z, Pan X, Zou Z, Ding Q, Wu G and Peng G: Increased SHP-1 expression results in radioresistance, inhibition of cellular senescence, and cell cycle redistribution in nasopharyngeal carcinoma cells. Radiat Oncol 10: 152, 2015.

16. Zhang J, Zou F, Tang J, Zhang Q, Gong Y, Wang Q, Shen Y, Xiong L, Breyer RM, Lazarus M, et al: Cyclooxygenase-2derived prostaglandin $\mathrm{E}_{2}$ promotes injury-induced vascular neointimal hyperplasia through the E-prostanoid 3 receptor. Circ Res 113: 104-114, 2013.

17. Schumacher Y, Aparicio T, Ourabah S, Baraille F, Martin A, Wind P, Dentin R, Postic C and Guilmeau S: Dysregulated CRTC1 activity is a novel component of $\mathrm{PGE}_{2}$ signaling that contributes to colon cancer growth. Oncogene 35: 2602-2614, 2016.

18. Wu K, Fukuda K, Xing F, Zhang Y, Sharma S, Liu Y, Chan MD, Zhou X, Qasem SA, Pochampally R, et al: Roles of the cyclooxygenase 2 matrix metalloproteinase 1 pathway in brain metastasis of breast cancer. J Biol Chem 290: 9842-9854, 2015.

19. Qiu X, Cheng JC, Chang HM and Leung PC: COX2 and PGE mediate EGF-induced E-cadherin-independent human ovarian cancer cell invasion. Endocr Relat Cancer 21: 533-543, 2014. 
20. Pan J, Tang T, Xu L, Lu JJ, Lin S, Qiu S, Chen G and K Tham IW: Prognostic significance of expression of cyclooxygenase-2, vascular endothelial growth factor, and epidermal growth factor receptor in nasopharyngeal carcinoma. Head Neck 35: 1238-1247, 2013.

21. Majumder M, Dunn L, Liu L, Hasan A, Vincent K, Brackstone M, Hess D and Lala PK: COX-2 induces oncogenic micro RNA miR655 in human breast cancer. Sci Rep 8: 327, 2018.

22. Le CP, Nowell CJ, Kim-Fuchs C, Botteri E, Hiller JG, Ismail H, Pimentel MA, Chai MG, Karnezis T, Rotmensz N, et al: Chronic stress in mice remodels lymph vasculature to promote tumour cell dissemination. Nat Commun 7: 10634, 2016.

23. Zhao CX, Luo CL and Wu XH: Hypoxia promotes 786-O cells invasiveness and resistance to sorafenib via HIF- $2 \alpha / \mathrm{COX}-2$. Med Oncol 32: 419, 2015

24. Kurtova AV, Xiao J, Mo Q, Pazhanisamy S, Krasnow R, Lerner SP, Chen F, Roh TT, Lay E, Ho PL, et al: Blocking PGE -induced tumour repopulation abrogates bladder cancer chemoresistance. Nature 517: 209-213, 2015.

25. Zhou W, Feng X, Ren C, Jiang X, Liu W, Huang W, Liu Z, Li Z, Zeng L, Wang L, et al: Over-expression of BCAT1, a c-Myc target gene, induces cell proliferation, migration and invasion in nasopharyngeal carcinoma. Mol Cancer 12: 53, 2013.

26. Khamaisi M, Katagiri S, Keenan H, Park K, Maeda Y, Li Q, Qi W, Thomou T, Eschuk D, Tellechea A, et al: PKC $\delta$ inhibition normalizes the wound-healing capacity of diabetic human fibroblasts. J Clin Invest 126: 837-853, 2016.

27. Liu T, Ding Y, Xie W, Li Z, Bai X, Li X, Fang W, Ren C, Wang S Hoffman RM, et al: An imageable metastatic treatment model of nasopharyngeal carcinoma. Clin Cancer Res 13: 3960-3967, 2007.

28. Campisi J: Aging, cellular senescence, and cancer. Annu Rev Physiol 75: 685-705, 2013.

29. Dirac AM and Bernards R: Reversal of senescence in mouse fibroblasts through lentiviral suppression of p53. J Biol Chem 278: $11731-11734,2003$

30. Yu Y, Fan J, Chen XS, Wang D, Klein-Szanto AJ, Campbell RL, FitzGerald GA and Funk CD: Genetic model of selective COX2 inhibition reveals novel heterodimer signaling. Nat Med 12 : 699-704, 2006

31. Zhu H, Kauffman ME, Trush MA, Jia Z and Li YR: A simple bioluminescence imaging method for studying cancer cell growth and metastasis after subcutaneous injection of Lewis lung carcinoma cells in syngeneic C57BL/6 mice. React Oxyg Species (Apex) 5: 118-125, 2018.

32. Choi EM, Kim SR, Lee EJ and Han JA: Cyclooxygenase-2 functionally inactivates p53 through a physical interaction with p53. Biochim Biophys Acta 1793: 1354-1365, 2009.
33. Liao Q, Zeng Z, Guo X, Li X, Wei F, Zhang W, Li X, Chen P, Liang F, Xiang B, et al: LPLUNC1 suppresses IL-6-induced nasopharyngeal carcinoma cell proliferation via inhibiting the Stat3 activation. Oncogene 33: 2098-2109, 2014.

34. Bourouba M, Zergoun AA, Maffei JS, Chila D, Djennaoui D, Asselah F, Amir-Tidadini ZC, Touil-Boukoffa C and Zaman MH: $\mathrm{TNF} \alpha$ antagonization alters NOS 2 dependent nasopharyngeal carcinoma tumor growth. Cytokine 74: 157-163, 2015.

35. Zhou TJ, Zhang SL, He CY, Zhuang QY, Han PY, Jiang SW, Yao H, Huang YJ, Ling WH, Lin YC, et al: Downregulation of mitochondrial cyclooxygenase-2 inhibits the stemness of nasopharyngeal carcinoma by decreasing the activity of dynamin-related protein 1. Theranostics 7: 1389-1406, 2017.

36. Braumüller H, Wieder T, Brenner E, Aßmann S, Hahn M, Alkhaled M, Schilbach K, Essmann F, Kneilling M, Griessinger C, et al: T-helper-1-cell cytokines drive cancer into senescence. Nature 494: 361-365, 2013.

37. Goel S, Wang Q, Watt AC, Tolaney SM, Dillon DA, Li W, Ramm S, Palmer AC, Yuzugullu H, Varadan V, et al: Overcoming therapeutic resistance in HER2-positive breast cancers with CDK4/6 inhibitors. Cancer Cell29: 255-269, 2016.

38. Li Y, Lei D, Swindell WR, Xia W, Weng S, Fu J, Worthen CA, Okubo T, Johnston A, Gudjonsson JE, et al: Age-associated increase in skin fibroblast-derived prostaglandin E2 contributes to reduced collagen levels in elderly human skin. J Invest Dermatol 135: 2181-2188, 2015.

39. Kim J, Vaish V, Feng M, Field K, Chatzistamou I and Shim M: Transgenic expression of cyclooxygenase-2 (COX2) causes premature aging phenotypes in mice. Aging (Albany NY) 8: 2392-2406, 2016 .

40. Han JA, Kim JI, Ongusaha PP, Hwang DH, Ballou LR, Mahale A, Aaronson SA and Lee SW: P53-mediated induction of Cox-2 counteracts p53- or genotoxic stress-induced apoptosis. EMBO J 21: 5635-5644, 2002.

41. Chan SY, Choy KW, Tsao SW, Tao Q, Tang T, Chung GT and Lo KW: Authentication of nasopharyngeal carcinoma tumor lines. Int J Cancer 122: 2169-2171, 2008.

This work is licensed under a Creative Commons Attribution-NonCommercial-NoDerivatives 4.0 International (CC BY-NC-ND 4.0) License. 